\title{
An Emerging System to Study Photosymbiosis, Brain Regeneration, Chronobiology, and Behavior: The Marine Acoel Symsagittifera roscoffensis
}

\author{
Enrique Arboleda, Volker Hartenstein, Pedro Martinez, Heinrich Reichert, Sonia Sen, \\ Simon Sprecher, and Xavier Bailly**
}

The acoel worm Symsagittifera roscoffensis, an early offshoot of the Bilateria and the only well-studied marine acoel that lives in a photosymbiotic relationship, exhibits a centralized nervous system, brain regeneration, and a wide repertoire of complex behaviors such as circatidal rhythmicity, photo/ geotaxis, and social interactions. While this animal can be collected by the thousands and is studied historically, significant progress is made over the last decade to develop it as an emerging marine model. The authors here present the feasibility of culturing it in the laboratory and describe the progress made on different areas, including genomic and tissue architectures, highlighting the associated challenges. In light of these developments, and on the ability to access abundant synchronized embryos, the authors put forward S. roscoffensis as a marine system to revisit questions in the areas of photosymbiosis, regeneration, chronobiology, and the study of complex behaviors from a molecular and evolutionary perspective.

\section{Dr. E. Arboleda}

Station Biologique de Roscoff

Place Georges Teissier

29680 Roscoff, France

Prof. V. Hartenstein

UCLA, MCDB

Charles E Young Drive South

Los Angeles, CA 90095

Dr. P. Martinez

Institut Català de Recerca i EstudisAvancats (ICREA)

Passeig de Lluís Companys, 23

08010 Barcelona, Spain

Prof. H. Reichert

Departement de Biologie

Universite de Fribourg

1700 Fribourg, Switzerland

Dr. S. Sen

Institute of Neuroscience

Institute of Molecular Biology

Howard Hughes Medical Institute

Eugene, OR 97403

Prof. S. Sprecher

Universite de Fribourg

1700 Fribourg, Switzerland

Dr. X. Bailly

CNRS, Station Biologique de Roscoff

29680 Roscoff, France

E-mail: xavier.bailly@sb-roscoff.fr

\section{Introduction}

Symsagittifera roscoffensis, also known as the Roscoff worm or the mint-sauce worm, is an acoel of the Convolutidae family. ${ }^{[1]}$ It has a rather simple cylindrical and flattened body, with no apparent head, an anterior portion exhibiting two photoreceptors flanking a spherical structure involved in gravito-sensing (i.e., the statocyst) ${ }^{[2]}$ and a ventral mouth from which algae are ingested to establish their characteristic photosymbiotic relationship. ${ }^{[3]}$ Adults (about 3-4 $\mathrm{mm}$ long, $550 \mu \mathrm{m}$ wide, and $80 \mu \mathrm{m}$ thick) are hermaphrodites, and during their gravid period (September to June in west France), they bear a white string of ovocytes, diagnostic of sexual maturity. Embryos develop inside a cocoon made of mucus secreted by the gravid animal (reviewed in ref. ${ }^{[2]}$ ).

The species has drawn scientific attention from the time of its first description mainly because of its abundance on sandy beaches during low tides (forming aggregations of millions of individuals), ${ }^{[4]}$ its conspicuous green color from its photosymbiotic relationship with green microalgae ${ }^{[5]}$ and the easy access to fertilized eggs and developing embryos ${ }^{[3]}$ (for historical background and general biological details see ref.[2]). Its presence has been reported from northwest France ${ }^{[3,6,7]}$ to the southern end of Portugal, ${ }^{[8]}$ including the Channel Islands ${ }^{[3,6]}$ and South Wales. ${ }^{[9,10]}$ The absence of additional records from the east coast of the UK certainly deserves further field exploration.

The phylogenetic position of acoelomorphs has been disputed over the years. This crucial debate pivots around the question of whether they are part of the deuterostomes or rather the sister group of all other bilaterians [reviewed in ref. ${ }^{[11]}$, with the most recent evidence supporting the latter. ${ }^{[12]}$ Being a member of the sister group of Bilateria, acoels become a system of unique potential to study the evolution of bilaterian features. ${ }^{[13]}$ In fact, this group might represent the best proxy we have for an ancestral bilaterian ${ }^{[14]}$ (or at least for a similar complexity).

In this paper, we review the practical and scientific advances made on the acoel $S$. roscoffensis as an emerging marine model in different areas of research. We cover what is known about the species as a vantage point to highlight its potential as a system to further explore such areas. The bulk of scientific work that 
now serves as the base to study subjects of current interest was done several decades ago. The revival of $S$. roscoffensis as a laboratory model has happened hesitantly over the last 10 to 20 years, largely as a result of introducing molecular techniques applied to resolving the phylogenetic position of acoelomorphs within the tree of life, and its consequent relevance in the EvoDevo field (e.g., regeneration, muscle development, nervous system evolution). This review ultimately aims to highlight also, and with fairness, some current methodological and conceptual limitations of the system, emphasizing the ongoing efforts to address them and with the aim of stimulating the interest of a broader scientific community in working with $S$. roscoffensis. The imminent publication of $S$. roscoffensis's genome and transcriptomes will certainly facilitate this process and will potentiate the investigation of a wide diversity of scientific problems.

\section{Symsagittifera roscoffensis as an Emerging Marine System to Study Key Areas of Research}

\subsection{A Marine System to Study Photosymbiosis}

Symbiosis with photosynthetic algae is common in the family Convolutidae (reviewed in ref. ${ }^{[15]}$ ), but some of the practical/ logistical reasons that make $S$. roscoffensis a particularly useful system to study photosymbiosis include the ability to manipulate the onset of the association, the possibility to induce the expulsion of the endosymbiotic algae (e.g., by bubbling $\mathrm{CO}_{2}{ }^{[16]}$ ), and the fact that animals do not feed, which makes the quantification of nutrient movement easier to interpret. ${ }^{[16]}$ In nature, the monospecific photosymbiotic association occurs with the green algae Tetraselmis convolutae (for a historical and taxonomical review of the identity of the endosymbiont see ref. [2]), and is considered as a high light-acclimated one in terms of photophysiology. ${ }^{[17]}$ Remarkably, the endosymbiotic algae are not internalized, but lay within the animal cells below the epidermis, in the so-called peripheral parenchyma. In laboratory conditions, and in the absence of other options, juveniles can ingest some closely related species of algae, establish the symbiotic relationship and grow. However, upon the addition of T. convolutae to the medium, all endosymbiotic algae will be replaced by it. ${ }^{[18,19]}$ In these cases, the photosynthesis/respiration ratio is not dependent on the algal species, but the number of endosymbiotic algae inside the juvenile animal seems to depend on the size of the algae itself. ${ }^{[20]}$ We have tested the ability of $S$. roscoffensis juveniles to ingest seven different species of the genus Tetraselmis (Figure 1). An early symbiotic relationship can be established with all tested species, which is not the case when more distantly related green algae like Dunaliella salina and Nanochloropsis sp. are provided. However, T. convolutae has a more visually dense and organized distribution over the body of the acoel. The photophysiology of T. convolutae in culture and in endosymbiotic state has been studied elsewhere, ${ }^{[17,20,21]}$ but a potential related benefit over other species of the genus Tetraselmis remains to be explored.

The specific mechanisms of recognition/expulsion and how much it resembles those of other photosymbiotic associations remain still unresolved. It is known, however, that algal multiplication inside young animals happens by asexual reproduction, since traces of mitosis ${ }^{[18]}$ and theca disintegration of individual algae ${ }^{[22]}$ can be seen in juvenile worms, but not in older adults. The acoel/algae association relies on using some physiological by-products (i.e., waste) generated by the other partner. The functional description of this relationship has been mainly done with a trophic approach, with the endosymbiotic algae transferring compounds such as sugars, amino-acids, ${ }^{[23]}$ and lipids. ${ }^{[24]}$ On the other side, the uric acid produced by the acoel (as a form of nitrogen waste) is a vital substrate for the algae to carry out photosynthesis. ${ }^{[16]}$ It is generally accepted that in animal photosymbiosis, the photosymbionts (e.g., algae) are generally exploited by their host (e.g., acoels) ${ }^{[25,26]}$ (but see ${ }^{[27]}$ ). Future holistic approaches combining metabolomics, proteomic, and differential transcriptomics will definitely aid to decipher this complex interaction network. Moreover, the ability to manipulate the onset of symbiosis means that a time course of events (with all molecular components followed in real time) can be studied. In this sense, $S$. roscoffensis also has the potential to become a key marine system to study the molecular underpinnings of symbiosis.

The number of endosymbiotic algae in adults has been estimated to be between $30.000 /$ worm $^{[20]}$ (in situ observation) and $70.000 /$ worm $^{[6]}$ (using a teflon homogenizer to disrupt the animal and a haemocytometer to count the algal cells). By disrupting the animal tissue, isolating the endosymbiotic algae cells, and counting them via flow cytometry, we have estimated an average of 121.400 endosymbionts per adult. An increase in the known number of algae inside the animal is relevant when extrapolations are being drawn for energetic budgets and production of metabolites in S. roscoffensis (e.g., ref. [28]).

\subsection{The Tri-Partite Association Acoel-Microalgae- Microbiome Plays a Critical Role in DMSP Production}

Endosymbiotic algae are also partially responsible for the strong odor emanated from physically disrupted acoels. It is caused by the production of volatile Dimethyl Sulfide (DMS), through the cleavage of DMSP produced by a DMSP-lyase in the $S$. roscoffensis/T. convolutae complex. ${ }^{[28]}$ Dimethylsulfoniopropionate (DMSP) is a highly abundant and important sulfur metabolite in marine and estuarine ecosystems. It is biosynthesized by bacteria, ${ }^{[29,30]}$ algae, plants, ${ }^{[31,32]}$ and even juvenile corals lacking endosymbionts. ${ }^{[33]}$ It can be used as an osmolyte (e.g., brackish ecosystems), antioxidant (e.g., thermal stress), predator deterrent (e.g., phytoplankton grazed by zooplankton), chemoatractor for tertiary consumers (e.g., birds and small carnivorous fish), cryoprotectant (e.g., polar algae), as a reduced carbon and sulfur source for bacteria, and by coral polyps as a signaling molecule to attract microbial communities necessary for coral health (reviewed in ref. ${ }^{[30,34]}$ ).

In the case of $S$. roscoffensis, DMSP is present in the endosymbiotic algae and possibly (due to its high concentration in symbiotic adults) in the body tissue of the acoel. ${ }^{[28]}$ Unlike in cultures of $T$. convolutae, experimental results show that osmoregulation is not the main role of DMSP in symbiotic adults. $^{[28]}$ Lysis of DMSP is enhanced by grazing on 
a

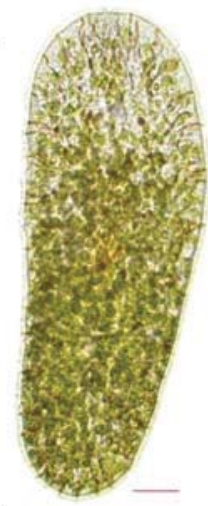

f

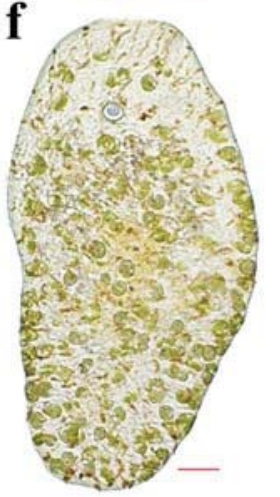

b

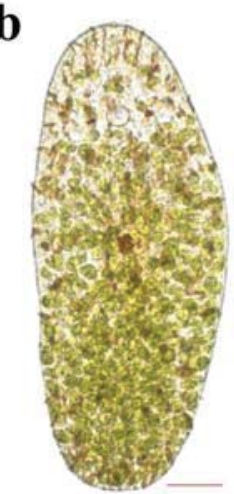

g

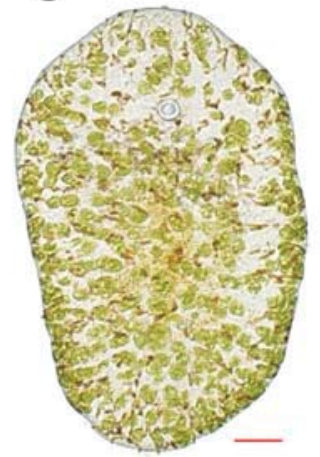

c

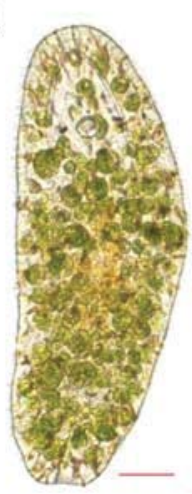

h

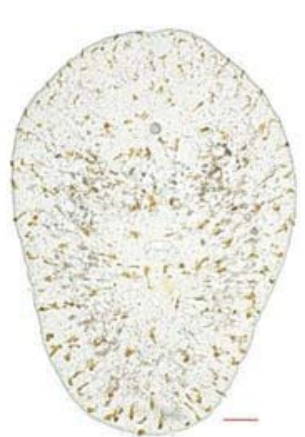

d

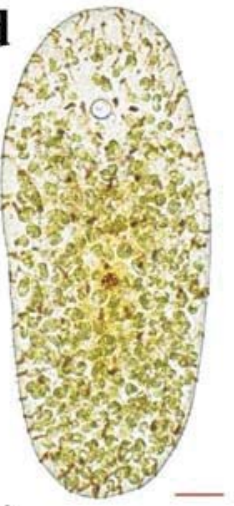

i

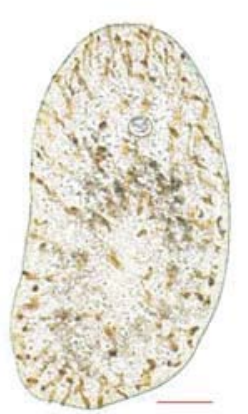

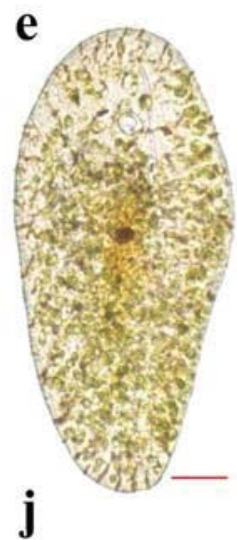

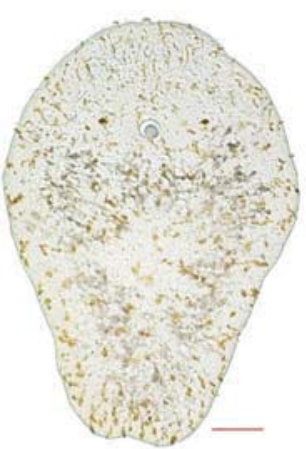

Figure 1. Juvenile S. roscoffensis are able to establish a symbiotic relationship with some species of the genus Tetraselmis, but not with other far-related green algae. a) Tetraselmis convolutae, (b) T. chuii, (c) T. marina, (d) T. rubens, (e) T. striata, (f) T. subcordiformis, (g) T. suecica, (h) Dunaliella salina, (i) Nanochloropsis sp., (j) aposymbiotic juveniles not exposed to any algae.

phytoplankton $^{[35]}$ and has been shown to deter protozoan herbivores. ${ }^{[36]}$ Considering how these acoels are recurrently exposed for long periods of time at the same location at extremely high densities, without being eaten, the role of DMSP as a natural predator deterrent cannot be excluded. Likewise, the role of DMSP as an antioxidant might explain the ability of $S$. roscoffensis populations to withstand exposition to high levels of light/UV/temperature and air exposure, as in the case of the coral holobiont ${ }^{[37]}$ and marine algal cultures. ${ }^{[38]}$

Most DMSP-producing species of phytoplankton have DMSP lyase activity. ${ }^{[39]}$ Interestingly, this is not the case for T. convolutae in culture, which means that lyase activity might come directly from the animal or, more likely, from the associated microbial community. ${ }^{[28]}$ In fact, this associated microbial community (i.e., the microbiome) is a major line of research open to be explored using S. roscoffensis as a holobiont system (i.e., animal + algae + microbes). Using flow cytometry, we have found that adults have a distinctive associated bacterial and viral community (XV unpublished), but barcoding, meta-omics, and physiological roles of the microbiome remains to be studied.

\subsection{Symsagittifera roscoffensis Exhibits Full Brain Regeneration and Localized Totipotent Stem Cells}

Symsagittifera roscoffensis can regenerate both the anterior and the posterior ends of its body ${ }^{[2,40]}$ (Figure 2a). Of note, and highly relevant as an experimental system, is their ability to regenerate a full brain from scratch. This is a rather unique feature and allows researchers to follow the regeneration process of a brain with remarkable detail. ${ }^{[2,41-46]}$ Planarians ${ }^{[47,48]}$ and acoelomorphs ${ }^{[49-}$

${ }^{51]}$ have distinctive totipotent stem cells (neoblasts) responsible for the renewal of all cell types during development, growth, and regeneration. ${ }^{[47,52]}$ For the first time, using EdU staining (i.e., marking DNA of dividing cells to follow cell proliferation), neoblasts on $S$. roscoffensis juveniles is presented (Figure 2b). This, and the link between neural development and behavior in S. roscoffensis, ${ }^{[40]}$ highlight very promising areas in which acoels are relevant experimental systems.

Studies on the early development of the S. roscoffensis nervous system suggest that the underlying genetic mechanisms are evolutionarily conserved and shared with other animal species, ${ }^{[45]}$ while related neuroanatomical studies of neurotransmitters and neuropeptides have provided insights into the overall organization of the nervous system. ${ }^{[53]}$ These studies together highlight that despite the comparably small number of neurons in the freshly hatched juvenile, the cellular repertoire is surprisingly diverse. These findings fundamentally challenge the notion that the nervous system in acoels is simple. However, the diversity of neurons by expression of neurotransmitters, neuropeptides, and receptors, as well as their connectivity pattern, remain largely unknown. Similarly, virtually nothing is known regarding the expression of transcription factors as terminal fate determinants. By using serial section electron 


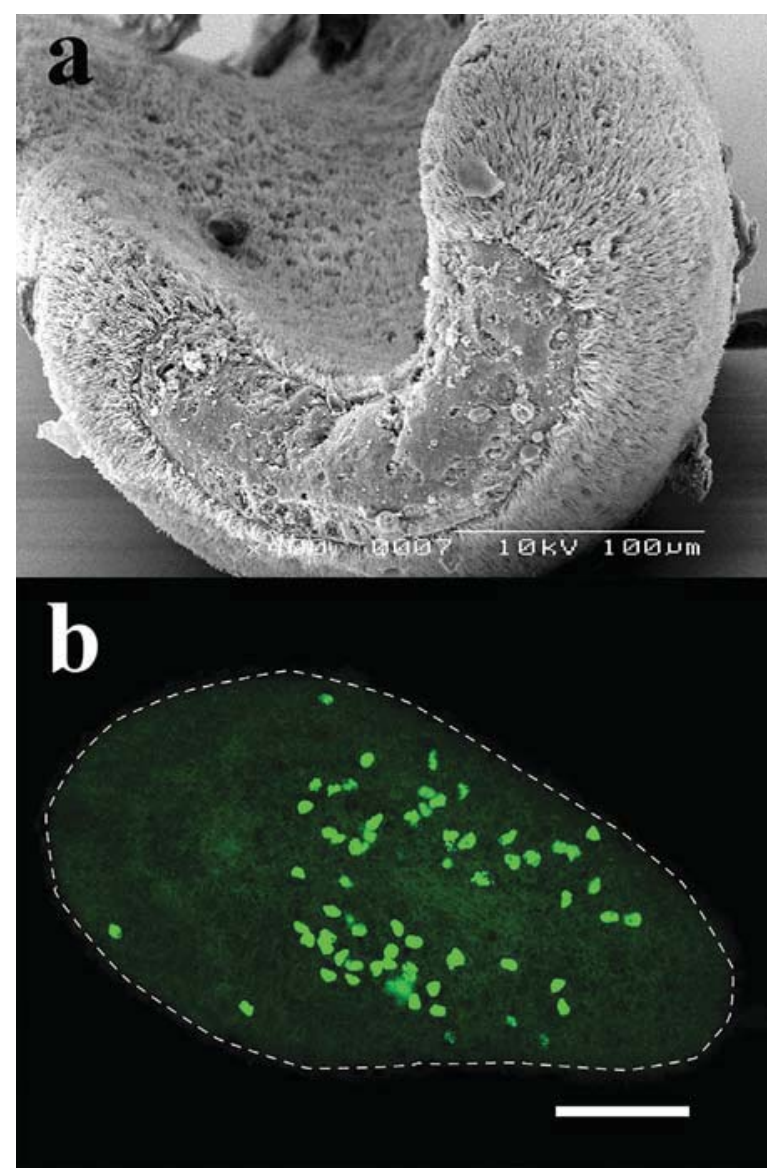

Figure 2. a) SEM image of an adult S. roscoffensis during its posterior regeneration process. b) Neoblasts (totipotent stem cells) stained with EdU on S. roscoffensis juveniles. Scale bar: 50 microns.

microscopy (SSTEM) we know the juvenile brain contains about 700 neurons (a full map of cell positions has been already generated; PM, SGS, and VH unpublished data; more below). Based on this experimental approach, three major classes of receptors can be distinguished (type I: monociliated receptors without a microvillar collar; type II monociliated receptors with collar; type III: multiciliated receptors), however how these cell types differ in the expression of specific cohorts of genes and what their actual function for the animal is remains to be determined. Interestingly, most of these receptors seem to be organized in close association with the brain or the cords. Based on available techniques, a promising, and feasible experimental approach would be to map the expression of genes using in situ RNA hybridization or the generation of antibodies. Recent advances in single-cell RNAseq in principle allows determination of the molecular organization of gene expression in any given cell of any organism, if a high-quality transcriptome is available and a single-cell suspension of viable cells can be generated. While this approach has not yet been applied in $S$. roscoffensis, it would provide a key data set on cellular diversity of the nervous system of this organism. The possibility of studying brain regeneration is a particularly interesting feature with biomedical and behavioral implications.

\subsection{A Species With Circatidal Rhythmicity and Identified Molecular Clock-Related Genes}

Marine organisms, from cyanobacteria and micro/macro algae to invertebrates and vertebrates, exhibit a variety of biological rhythms related to the cycling of the sun, the moon and/or the tides (reviewed in ref. ${ }^{[54-56]}$ ). Symsagittifera roscoffensis is not an exception, and a clear circatidal rhythm had already been reported in the early $1900 \mathrm{~s} \cdot{ }^{[3,57,58]}$ Animals freshly collected in the field and brought to the laboratory will continue their rhythmic oscillation (ascending and descending in the culture vessel) according to the natural tides. The cycling starts to diminish after 8 days under constant light/dark conditions and it is completely absent if animals are placed in complete darkness (i.e., the rhythm does not appear to free-run). ${ }^{[3]}$ There is a clear anticipation of the tidal cycle, neatly highlighted by the fact that if animals are collected directly after the colonies emerge and individuals are put in darkness for periods of either 1,2 , or $3 \mathrm{~h}$, when they are exposed again to the light, those which had only $1 \mathrm{~h}$ in darkness descend first, followed by those exposed for $2 \mathrm{~h}$, and so on. ${ }^{[3]}$

We are currently re-visiting the circatidal cycling in laboratory conditions. Preliminary results show a clear circatidal rhythm under constant temperature and light/dark cycles (Figure 3), although easily disrupted by random vibrations and/or artificial light at night (even if for short periods of time). Ongoing efforts (by P. Olivieri and PM) to identify circadian clock-related genes from the genome of $S$. roscoffensis have found homologues of Timeless, a Cryptochrome, a Photolyase, a CREB-binding protein, and Arnt (genes involved in light entrainment or in core functioning of the molecular clock depending on the species). Identification of additional related genes, further characterization of their circadian/circatidal transcriptional oscillation and their specific roles in $S$. roscoffensis, and the chance to study a possible cross-talk between the algae's molecular clock and that of the acoel, are aspects that will significantly advance the field of chronobiology.

\subsection{Symsagittifera roscoffensis has a Broad Behavioral Repertoire That Includes Tactic Movements and Social Responses}

The availability of large numbers of animals that can easily be collected in nature, transported, and maintained for weeks to months, make $S$. roscoffensis amenable for behavioral studies. They exhibit a behavioral repertoire that includes phototaxis, ${ }^{[21,40,59]}$ geotaxis, ${ }^{[3,57]}$ rheotaxis, ${ }^{[59]}$ thermotaxis, ${ }^{[59]}$ responses to mechanical stimulation and vibration, ${ }^{[40]}$ and even social responses influenced by the presence of conspecifics. ${ }^{[60]}$ The majority of experimental evidence was obtained over a century ago, and there is therefore considerable scope for further exploration with modern technologies and novel hypotheses. Positive phototaxis can easily be tested in the laboratory with normal white light ${ }^{[40]}$ even on juveniles hatched after a few hours, ${ }^{[59]}$ but responses to specific wavelengths are not fully clear. Some authors ${ }^{[3,59]}$ report positive phototaxis toward white and green light, but a weak negative tropism toward red light. 


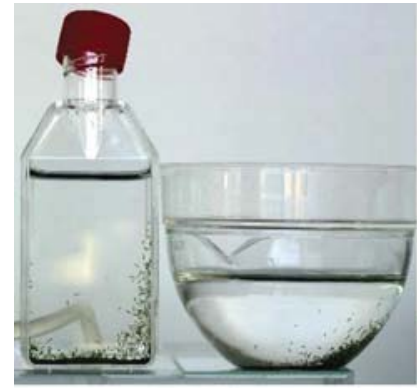

High Tide

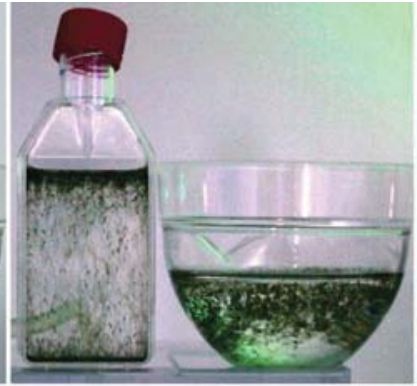

Low Tide

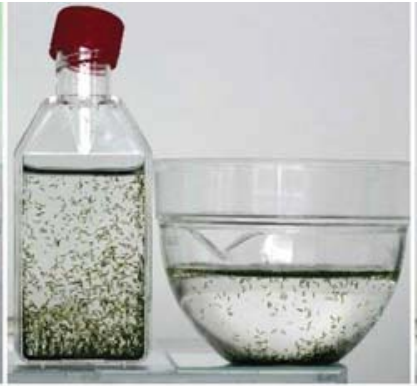

High Tide

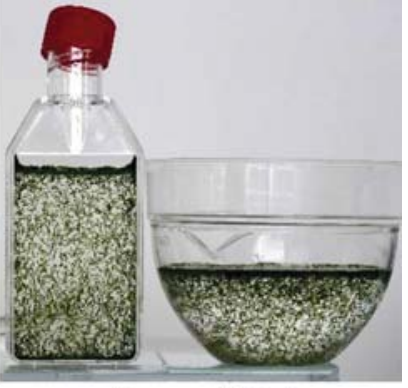

Low Tide

Figure 3. Freshly collected S. roscoffensis adults display a circatidal activity pattern in captivity. Images were taken every $\approx 6 \mathrm{~h}$, corresponding with the maximum time of high and low tides in nature. Light-dark conditions followed those in nature, and individual photographs from night hours (taken with high exposure time) where digitally overexposed to increase visibility.

Others, ${ }^{[21]}$ have shown an active movement of adults toward areas illuminated with green and blue light, but not with red light; leading to the interpretation that red light cannot be perceived by the animal. Animals under experimental conditions are also known to avoid low and high (potentially damaging) light intensities. ${ }^{[17]}$ Geotactic movement, in the form of a quick vertical retreat upon mechanical disturbance, was one of the conspicuous characteristics that drew naturalists' attention to $S$. roscoffensis. ${ }^{[3,4,57]}$ The statocyst is thought to be critical for gravity sensing, with juveniles naturally lacking statocysts failing to react to gravity ${ }^{[3,59]}$ and, with adults divided transversely, only the anterior part of the body maintaining the geotactic response. ${ }^{[59]}$ Furthermore, when animals simultaneously experience a vertical plane (i.e., gravity force) and a centrifugal force acting in a diagonal direction, the animals place themselves in the resultant of the two forces. ${ }^{[61]}$ The rheotactic response of adults is said to be dependent on the strength of the flow. ${ }^{[59]}$ Thus, individuals in a moderate stream of water will tend to move toward it, but a gradual increase of the flow will make the animals stick to the ground and finally to contract themselves and detach. ${ }^{[59]}$ Thermotaxis has only been briefly described for $S$. roscoffensis. They are thought not to have a thermotactic response at normal temperatures, and only when temperature reaches a lethal $38^{\circ} \mathrm{C}$ do adults react negatively against its point of origin. ${ }^{[59]}$ However, when adults are driven by positive phototaxis to the end of a cylinder, where the water is later heated gradually, the animals will not move back and eventually die due to the high temperature. ${ }^{[3]}$ In terms of responses to mechanical stimulation and vibration, it is robustly and stereotypically displayed in adults by a body contraction behavior, which remains unchanged even in the absence of the brain (i.e., after decapitation). ${ }^{[40]}$ Symsagittifera roscoffensis has also been posited as an ideal system to study how individual behaviors can lead, through collective movement, to social assemblages. ${ }^{[60]}$ When placed on a horizontal surface, adults actively interact with their neighbors, leading to a clock-wise circular milling aggregation behavior ${ }^{[00]}$ that might be related to photoprotection by shading each other. ${ }^{[6]}$ Moreover, when a group of adults that still has a clear circatidal rhythm is mixed with a group that has lost it, all individuals will exhibit the same behavioral response as the group with more individuals in the mix. ${ }^{[58]}$ This clearly suggests a social behavior component that is either able to bypass a predetermined individual response or to reacquire it at the behavioral level (although at the physiological level of the internal clock this remains to be tested). Finally, nothing is known about chemotaxis in S. roscoffensis. Variation in seawater composition by adding salt, sugar, alcohol, colorants, or even decomposing adults, can impact the normal geotactic and phototactic responses, ${ }^{[58]}$ but this seems to be more related to the general well-being of the animals than to a physiological disruption of the taxis. The recent availability of genomic/transcriptomic resources should provide us with a window to investigate the molecular basis of all these behaviors.

\section{Relevant Efforts to Bring Symsagittifera roscoffensis as an Emerging Model System}

\subsection{Life Cycle of Symsagittifera roscoffensis can be Completed in the Laboratory}

In 1968 Luigi Provasoli, a pioneer and worldwide expert in isolation, culturing, and domestication of microalgae, revealed he was able to culture $S$. roscoffensis for several generations in the laboratory. ${ }^{[18]}$ He also succinctly described a protocol mentioning the use of algae growth media. As S. roscoffensis does not feed, but relies on photosynthetates from Tetraselmis convolutae, it was indeed an important decision to feed the microalgae. Inspired by some of these indications, and with the idea of mimicking as much as possible the natural environment, we managed after many trials to complete the life cycle within 2 to 3 months in the laboratory, and have replicated this for 3 generations. Here is a sketch of the procedure:

1. From gravid adults to cocoons: Gravid acoels are collected on the shore during low tides and kept in filtered seawater $\left(14{ }^{\circ} \mathrm{C}\right.$ and illuminated 10:14 light:dark with T5 lamps of $\approx 6000$ Kelvin). Animals synthesize, with the mucus they abundantly secrete, translucent cocoons containing between 10 and 20 developing embryos.

2. Hatching: Non-symbiotic juvenile embryos, surrounded by a chorionic membrane, develop directly (no metamorphosis steps) within 4 to 5 days into a translucent juvenile of around $500 \mu \mathrm{m}$ in length. They hatch inside the cocoon and swim 

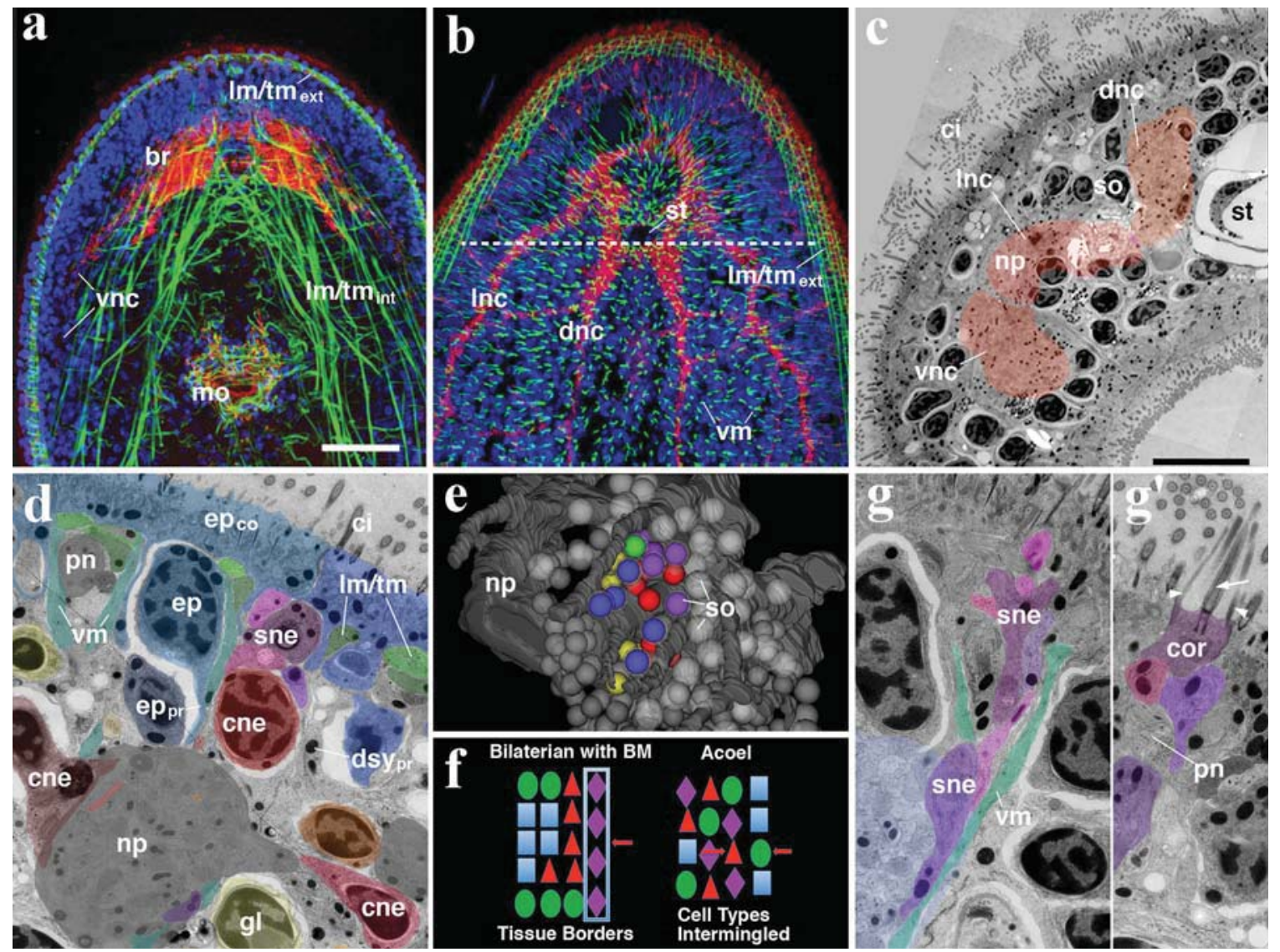

Figure 4. Cellular architecture of S. roscoffensis. a, b) Z-projections of horizontal confocal sections of the anterior end of an adult worm. Labeling of muscle by phalloidin (green), nervous system by anti-synaptotagmin (red), and nuclei with DAPI (blue). a) Deep focal plane at level of brain neuropil (br), ventral nerve cord (vnc) and mouth opening (mo). b) Superficial level with dorsal and lateral nerve cord (dnc, Inc). Internal and external network of longitudinal and transverse fibers $\left(\mathrm{Im} / \mathrm{tm}_{\mathrm{int}}, \mathrm{Im} / \mathrm{tm}_{\mathrm{ext}}\right)$ and densely spaced vertical muscle fibers $(\mathrm{vm})$. c) Electron micrograph of cross section of left half of juvenile S. roscoffensis at level of statocyst st; hatched line in (b) indicates level of section in (c). At level shown, brain neuropil (np; shaded pink) makes a transition into the three nerve cords. Somata (so) cells form layer surrounding neuropil and nerve cords. d) Electron micrograph of cross section at high magnification. Individual somata were identified with particular cell types (cne central neuron; ep epidermis cell; gl gland cell; sne sensory neuron). These cell types are intermingled within the layer of somata surrounding neuropil (np). Note profuse ensheathing processes surrounding most somata; sheaths are formed by epidermal cells $\left(\mathrm{ep}_{\mathrm{pr}}\right)$, as well as the digestive syncytium $\left(\mathrm{dsy}_{\mathrm{pr}}\right)$. Intermingling of cell types is also illustrated in (e), which shows digital 3D model of anterior part of S. roscoffensis juvenile in dorso-anterior view. Neuropil is shaded in dark gray. Somata of all cells of left half of the animal are rendered in light gray. Cluster of 25 contiguous somata was reconstructed from serial stack and identified with different cell types, as indicated by coloring. f) Schematic representation of intermingling of cell types in acoel, in contrast to most other bilaterians where basement membranes (BM) separate tissues with different cell types. (g, g') Electron micrographs showing details of bundled peripheral processes of sensory neurons (sne). One process ends as a collared receptor (cor); note large central cilium (arrow) flanked by collar of microvilli (arrowheads). Dendrite bundle is flanked by vertical muscle fibers and peripheral nerve (pn). Other abbreviations: ci cilia; ep co epidermal covering. Scale bars: 20 microns.

until they rupture the wall. Juveniles do not survive more than 15-20 days in the laboratory if their symbiotic partner is not provided.

3. Inducing a sustainable photosymbiosis: Adding a small amount of free-living T. convolutae microalgae in a recipient containing freshly hatched juveniles is enough for triggering the functional and sustainable partnership animal/microalgae. Juveniles become green within a week and then start to grow.

4. Reaching sexual maturity: The pivotal trick is to provide Provasoli ES medium $(1-2 \%)^{[62]}$ for an appropriate in-hospite photosynthetic activity. Empirically, it is important to find a trade-off between light, seawater quality/quantity and density of animals. As the latter constitutively produce mucus, a microbial consortium co-develops and, in closed seawater circulatory system, accumulates and forms a biofilm that leads to an unbalanced environment not suitable for the animals. Therefore, seawater must be changed regularly.

\subsection{Structural and Cytological Analyses Highlight a Spatial Segregation and Intermingle of Cell Bodies in Symsagittifera roscoffensis}

Acoels are characterized by a number of unusual morphological features. For one, basement membranes that in other metazoans 

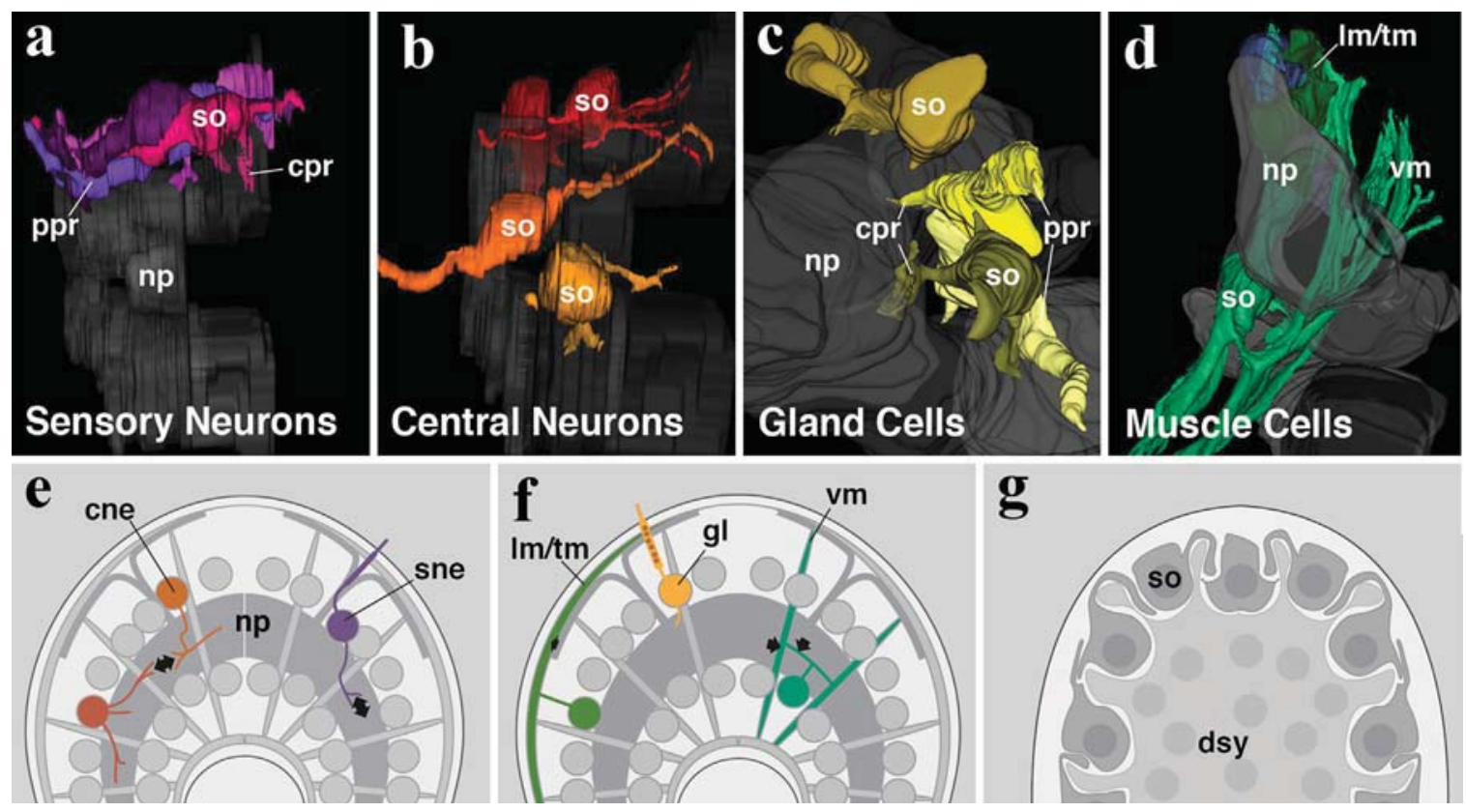

Figure 5. Digital 3D models of different cell types, based on serial reconstruction of EM stack. a) Sensory neurons and (b) central neurons are shown in lateral view (anterior to the left, dorsal up); (c) gland cells and (d) muscle cells in anterior view. All cell types have central processes (cpr) that penetrate neuropil (np); sensory neurons and gland cells form peripheral processes (ppr) ending in receptors and secretory openings, respectively. Central neurons are multipolar (as the one rendered in red), bipolar (as the one in orange), or unipolar (not shown). e-g) Schematic representation of $S$. roscoffensis architecture. e) Arrangement of processes and somata of central and sensory neurons (cne, sne) and (f) gland cells and muscle cells ( $\mathrm{gL}$, vm, $\mathrm{Im} / \mathrm{tm}$ ). Arrows indicate potential synaptic connection within neuropil. g) Digestive syncytium (dsy) emitting sheath processes around somata (so) of many cells.

separate tissues such as epidermis, muscle, nervous system, and gut, are absent. Virtually all cells have unusual shapes, in the sense that cell bodies (somata, consisting of a nucleus surrounded by cytoplasm) and functional compartments (e.g., muscle fiber, nerve fiber, epidermal layer) are spatially separated. Somata of epidermal cells are sunken beneath the dense network of muscle processes, forming an outer layer containing large, spherical nuclei (Figure 4). Most other cell bodies have smaller, ellipsoid nuclei that are clustered in a deeper cell mass that surrounds the brain neuropil and nerve cords (Figure 4). Characteristically, in this mass, different cell types (central and sensory neurons, muscle cells, gland cells and neoblasts-stem cells) are intermingled, forming an "amalgam" of cells (Figure 4).

An ongoing analysis of serially sectioned and electron optically imaged S. roscoffensis juveniles (B. Gavilan, PM, VH, $\mathrm{SSp}$ ) is attempting to reconstruct in detail the shape and pattern of cell types that constitute the acoel body. Representative examples of neurons, gland cell, and muscle cells are shown in (Figure 5); in all cases, the small cell bodies flank the neuropil, and send processes of different length into it, where synaptic contacts are established. In addition, cell bodies emit centrifugal processes that contribute to the muscle net (in the case of muscle cells), or penetrate the epidermal layer to form gland necks (gland cells) or sensory dendrites (receptor cells). Processes of central neurons are confined to the neuropil, where they form longitudinal or commissural fibers that give off short branches at regular intervals. Serial EM will allow for more detailed reconstructions of neuronal connections, ultimately revealing the "connectome" of the $S$. roscoffensis nervous system.

The second highly unusual morphological feature of $S$. roscoffensis, and other derived acoel species, is the absence of a cellular digestive system. Instead, the center of the animal is filled with a syncytial mass (i.e., digestive syncytium) that contains numerous nuclei. The digestive syncytium emits processes in all directions; that penetrate in between all other cells and form flat sheaths that envelop the cell bodies (Figure 4).

Efforts to map comprehensively the distribution of cell types in the animal is uncommon in "non-model" organisms and, in this sense, $S$. roscoffensis becomes a unique example.

\subsection{A Growing Set of Molecular Techniques and Genomic Resources Opens New Research Possibilities in Symsagittifera roscoffensis}

An increment in research laboratories interested on working with $S$. roscoffensis over the last decades has facilitated the development of molecular techniques specific for this system. Single (colorimetric) and double Fluorescent In Situ Hybridization (FISH) methodologies in all stages of development (embryos, juveniles and adults) are nowadays available. ${ }^{[45,46,63]}$ FISH allows mapping of more than one gene at a time and thus visualization of relative domains of expression. 


\section{a}
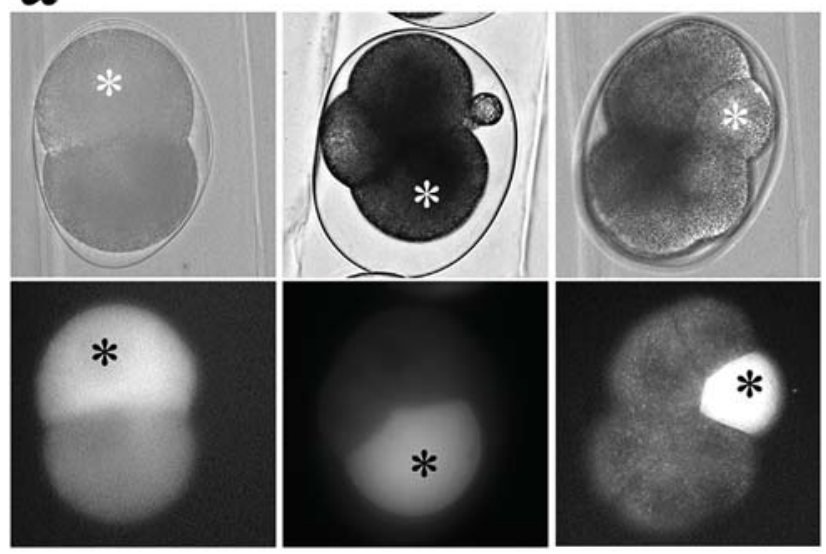

b
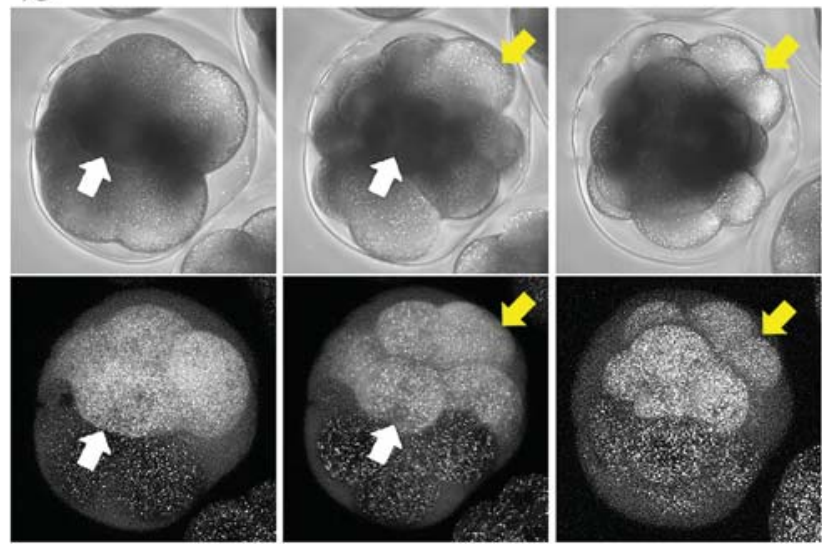

Figure 6. Preliminary results of microinjection on S. roscoffensis. a) Single cell injections during different early developmental stages. Pictures were taken immediately after microinjection. b) Follow-up on individual cells dividing over time (white or yellow arrows). For both panels, top row is brightfield image and bottom row is its correspondent fluorescent image. Embryos were injected with AlexaFluor 488 (1:10) either in $10 \mathrm{mM}$ HEPES or $1 \times$ PBS, and observed on a Nikon epifluorescence microscope.

Immunochemistry is also used regularly, either using commercial antibodies or a new generation of species-specific antibodies raised using the recently available EST data. This technique has led, for example, to the description of the molecular architecture of muscles in $S$. roscoffensis ${ }^{[64]}$ or its central nervous system. ${ }^{[45]}$ Unlike older animals, there are still some technical challenges in performing immunochemical reactions in embryos due to the cocoon membranes. The use of real-time quantitative PCR (RTqPCR) on S. roscoffensis has not been reported in the literature, but $18 \mathrm{~S}$ ribosomal and elongation factor 1-alpha $(\mathrm{EF} 1 \mathrm{a})^{[65]}$ as reference genes have been successfully tested (EA and K. Tessmar-Raible, unpublished).

Microinjection techniques on S. roscoffensis are still at an early stage, but preliminary results are encouraging. We have injected a total of 462 early developing embryos with a fluorescent dye (10 mM HEPES or 1X PBS with 1:10 AlexaFluor 488). During our trials almost half of the embryos ruptured upon injection, but $82 \%$ of the surviving injected hatched and developed into juveniles. Although these fluorescent markers get diluted over cell divisions, it was possible to visualize the injected cells immediately after manipulation and to follow them over three to four rounds of division (Figure 6). In developing microinjection in $S$. roscoffensis, certain aspects proved to be most challenging. The cytoplasm of the embryos is particularly viscous and sticky, resulting in frequent clogging of the needle. Furthermore, unless retracted with extreme care, the needle tore away portions of the membrane resulting in a ruptured cell (the primary reason for most of the failed injections). These embryos also have an extremely tough chorionic membrane, within which the embryo is suspended. Therefore, the snug mounting of the embryos was critical to successful injections, by allowing the chorionic membrane to remain in close contact with the embryos and facilitating the penetration of the needle thorough both the chorionic and the cell membrane. Mechanical removal of the chorionic membrane made the injection process much easier and the success rates higher, but this is a laborious and time consuming process that would potentially be improved by chemical removal of the membrane. Microinjection in $S$. roscoffensis would open exciting new research possibilities, of which cell fate mapping, overexpression, knockdown, expression domains, and genome editing are just a few general examples.

Regarding the genomic resources, over the years 2012-2016, within the international consortium (of which P.M. and S.S. are members) in charge of sequencing diverse Xenoacelomorpha genomes, there has been a considerable effort to sequence the genome of $S$. roscoffensis (from aposymbiotic hatchlings) and to construct a large EST collection from a mix of embryonic stages. Based on the assembly of the first draft genome, the estimated genome size of $S$. roscoffensis is $1.4 \mathrm{Gbp}$; much larger than that of Xenoturbella bocki $(\approx 150 \mathrm{Mbp})$ and that of the endosymbiont $T$. convolutae ( $\approx 28 \mathrm{Mbp})$. The annotated genes, with special focus on the annotation of families of transcription factors and other developmental regulators, are also being used to reanalyze the phylogenetic position of this group within the metazoan tree of life. The consortium is also looking at the structure of the genome, including intron/exon structure, presence of repetitive elements, transposons, microRNAs, etc. A draft genome and some transcriptomes (embryos and juveniles) are available, though not yet publicly accessible, and have been used in related research papers. ${ }^{[66-69]}$

The mapping of genes within the genome has been (and could be further) aided by the use of an arrayed Bacterial Artificial Chromosome (BAC) library produced from adults, which means the inclusion of the genome of the symbiotic algae. The BAC library currently has an average insert size of $\approx 100 \mathrm{~kb}$ and has been used to determine the genomic sequences around all the Hox subset of homeotic genes. ${ }^{[63]}$ Moreover, it has been possible to perform FISH on metaphase chromosomes, ${ }^{[63]}$ a critical technique to understand synteny relationships or to conduct regulatory analysis.

Finally, we are currently working on the transgenesis of the symbiotic algae, opening a novel avenue to study symbiosis, chronobiology, and behavior. What is the role of the endosymbiotic algae on these processes? The aim is to follow up with a transcriptomic and genomic analysis toward establishing gene editing techniques in Tetraselmis and to study possible horizontal gene transfer. 


\section{Current Challenges and Needs to Further Develop the System}

Despite the advances presented before, maintaining continuous generations of animals is not a trivial task. It will be ideal to adventure into the generation of isogenic lines, reducing the expected amount of polymorphism in the genetic samples obtained in nature.

There is a clear need to develop methodologies to knockdown genes. While RNA interference (RNAi) works for other acoels, it has never been attempted with $S$. roscoffensis. Ideally, additional methodologies such as CRISPR CAS9 genome editing technology should also be incorporated, so the role of genes can be analyzed easily and in a high throughput manner.

The early embryology of the animals has not been addressed using modern techniques. The only descriptions of early cleavage stages, from over a century ago, are partially in contradiction. ${ }^{[70,71]}$ Lineage tracing methods should be implemented, which also means fine-tuning the efforts on microinjection techniques presented above. Moreover, a systematic approach to single cell sequencing during the early development of acoels should provide a window to the changing patterns of gene expression in all lineages of the embryo.

There are also challenges and needs on the biological and ecological sides. The biogeography and detailed distribution of both S. roscoffensis and T. convolutae (including DNA barcoding) are of particular interest. Besides the aforementioned lack of records from the east coast of the UK, determination of any possible overlap with other photosymbiotic acoels as well as the distribution range of $T$. convolutae will help to better understand the association. In fact, DNA barcoding of acoelomorphs in benthic and pelagic habitats has already revealed an unexpected taxonomic richness, including discovery of a new clade in the deep sea ecosystem. ${ }^{[72]}$

\section{Conclusions}

Besides its phylogenetic position that accounts for the closest relative to extant bilaterians, there are several advantages in the $S$. roscoffensis system that are worth highlighting. Foremost, the ability to complete the life cycle and to maintain cultures in the laboratory, butalso, when it comes to large-scale studies involvingomics technologies, a key aspect is the possibility of accessing large amounts of biological material, including thousands of almost synchronized embryos. This is a species for which we have a varied and, for the most part, well described baseline of knowledge on the research areas reviewed here. This anatomical, behavioral, physiological, and practical knowledge needs to be merged (and updated) with the use of modern molecular techniques; a process that will certainly benefit from the forthcoming availability of the genome of $S$. roscoffensis to the scientific community.

Rather than being a well-established model (although it in the way of becoming one), S. roscoffensis is a highly useful marine system for investigating biological phenomena that go beyond the particular species. We have presented practical, phylogenetic, experimental, and biological strengths of $S$. roscoffensis to potentiate (and to promote) the use of this system to address relevant biological, physiological, and developmental/evolutionary questions. The more people that work on the system and the more accessible the system is to scientists; the quicker new techniques will be developed.

\section{Acknowledgments}

E.A. was funded by the Region Bretagne (France). S. Sen was funded by the Wadhwani Foundation. Flow cytometry was performed by Dominique Marie in the Adaptation et Diversité en Milieu Marin lab (UMR 7144) at the Station Biologique de Roscoff (France). Nolwenn Huon de Kermadec performed the experiments on circatidal behavior at the Station Biologique de Roscoff (France). Elena Perea (PM Lab) contributed with the SEM and EdU images on Figure 2.

\section{Conflict of Interest}

The authors declare no conflict of interest.

\section{Keywords}

emerging model system, endosymbiosis, holobiome, microinjection, neoblasts, photosymbiosis, Tetraselmis convolutae

Received: June 8, 2018

Revised: July 23, 2018

Published online: August 27, 2018

[1] U. Jondelius, A. Wallberg, M. Hooge, O. I. Raikova, Syst. Biol. 2011, 60,845 .

[2] X. Bailly, L. Laguerre, G. Correc, S. Dupont, T. Kurth, A. Pfannkuchen, R. Entzeroth, I. Probert, S. Vinogradov, C. Lechauve, M.-J. GaretDelmas, H. Reichert, V. Hartenstein, Front. Microbiol. 2014, 5, 498.

[3] F. Keeble, Plant-Animals: A Study in Symbiosis. University Press, Cambridge, England 1910.

[4] P. Geddes, Proc. R. Soc. Lond. 1879, 28, 449.

[5] F. Keeble, F. W. Gamble, Proc. R Soc. Lond. B 1905, 77, 66.

[6] S. A. Doonan, G. W. Gooday, Mar. Ecol. Prog. Ser. 1982, 8, 69.

[7] M.-A. Selosse, Acta Bot. Gallica 2000, 147, 323.

[8] L. F. Carvalho, C. Rocha, A. Fleming, C. Veiga-Pires, J. Aníbal, Mar. Pollut. Bull. 2013, 75, 150.

[9] C. Mettam, J. Mar. Biol. Assoc. U. K. 1979, 59, 251.

[10] A. E. Mcfarlane, J. Mar. Biol. Assoc. U. K. 1982, 62, 235.

[11] I. Ruiz-Trillo, J. Paps, Org. Divers. Evol. 2016, 16, 391.

[12] J. T. Cannon, B. C. Vellutini, J. Smith, F. Ronquist, U. Jondelius, A. Hejnol, Nature 2016, 530, 89.

[13] A. Hejnol, K. Pang, Curr. Opin. Genet. Dev. 2016, 39, 48.

[14] J. Baguñà, M. Riutort, BioEssays News Rev. Mol. Cell. Dev. Biol. 2004, 26, 1046.

[15] J. Melo Clavijo, A. Donath, J. Serôdio, G. Christa, Biol. Rev. Camb. Philos. Soc. 2018, https://doi.org/10.1111/brv.12430 [Epub ahead of print]

[16] J. E. Boyle, D. C. Smith, Proc. R Soc. Lond. B 1975, 189, 121.

[17] J. Serôdio, R. Silva, J. Ezequiel, R. Calado, J. Mar. Biol. Assoc. U. K. 2011, 91, 163.

[18] L. Provasoli, T. Yamasu, I. Manton, J. Mar. Biol. Assoc. U. K. 1968, 48, 465.

[19] A. E. Douglas, J. Mar. Biol. Assoc. U. K. 1983, 63, 419

[20] K. Nozawa, D. L. Taylor, L. Provasoli, Biol. Bull. 1972, 143, 420. 
[21] M. Nissen, D. Shcherbakov, A. Heyer, F. Brümmer, R. O. Schill, J. Exp. Biol. 2015, 218, 1693.

[22] J. L. Oschman, J. Phycol. 1966, 2, 105.

[23] B. P. Kremer, Mar. Biol. 1975, 31, 219.

[24] H. Meyer, L. Provasoli, F. Meyer, Biochim. Biophys. Acta 1979, 573, 464.

[25] E. T. Kiers, S. A. West, Curr. Biol. 2016, 26, R66.

[26] C. D. Lowe, E. J. Minter, D. D. Cameron, M. A. Brockhurst, Curr. Biol. 2016, 26, 207.

[27] H. Malcolm, H. April, Biol. Rev. Camb. Philos. Soc. 2012, 87, 804.

[28] S. A. V. Bergeijk, L. J. Stal, Mar. Biol. 2001, 138, 209.

[29] A. R. J. Curson, J. Liu, A. Bermejo Martínez, R. T. Green, Y. Chan, O. Carrión, B. T. Williams, S.-H. Zhang, G.-P. Yang, P. C. Bulman Page, X.-H. Zhang, J. D. Todd, Nat. Microbiol 2017, 2, 17009.

[30] H. A. Bullock, H. Luo, W. B. Whitman, Front. Microbiol. 2017, 8, 637.

[31] J. S. Dickschat, P. Rabe, C. A. Citron, Org. Biomol. Chem. 2015, 13.

[32] A. V. Borges, W. Champenois, Aquat. Bot. 2015, 125, 72.

[33] J.-B. Raina, D. M. Tapiolas, S. Forêt, A. Lutz, D. Abrego, J. Ceh, F. O. Seneca, P. L. Clode, D. G. Bourne, B. L. Willis, C. A. Motti, Nature 2013, 502, 677.

[34] G. A. Nevitt, Integr. Comp. Biol. 2011, 51, 819.

[35] J. W. Dacey, S. G. Wakeham, Science 1986, 233, 1314.

[36] G. V. Wolfe, M. Steinke, G. O. Kirst, Nature 1997, 387, 894.

[37] E. S. M. Deschaseaux, G. B. Jones, M. A. Deseo, K. M. Shepherd, R. P. Kiene, H. B. Swan, P. L. Harrison, B. D. Eyre, Limnol. Oceanogr. 2014, 59, 758.

[38] W. Sunda, D. J. Kieber, R. P. Kiene, S. Huntsman, Nature 2002, 418, 317.

[39] D. C. Yoch, Appl. Environ. Microbiol. 2002, 68, 5804.

[40] S. G. Sprecher, F. J. Bernardo-Garcia, L. van Giesen, V. Hartenstein, H. Reichert, R. Neves, X. Bailly, P. Martinez, M. Brauchle, Biol. Open 2015, 4, 1688.

[41] A. Bery, P. Martínez, Acta Zool. 2010, 92, 383.

[42] I. L. Dittmann, T. Zauchner, L. M. Nevard, M. J. Telford, B. Egger, J. Morphol. 2018, 279, 589.

[43] P. Martínez, E. Perea Atienza, B. Gavilán, C. Fernandez, S. Sprecher, Invertebr. Zool 2017, 1414, 32.

[44] P. Martínez, V. Hartenstein, S. G. Sprecher, Oxford Res. Encyclopedia Neurosci (Ed: S. M. Sherman), Oxford University Press, New York 2017.

[45] E. Perea-Atienza, S. G. Sprecher, P. Martínez, EvoDevo 2018, 9, 8.

[46] H. Semmler, M. Chiodin, X. Bailly, P. Martinez, A. Wanninger, Dev. Growth Differ. 2010, 52, 701.

[47] A. R. Gehrke, M. Srivastava, Curr. Opin. Genet. Dev. 2016, 40, 131.
[48] S. J. Zhu, B. J. Pearson, Curr. Opin. Genet. Dev. 2016, 40, 74

[49] A. E. Bely, J. M. Sikes, J. Biol. 2010, 9, 14.

[50] K. De Mulder, G. Kuales, D. Pfister, M. Willems, B. Egger, W. Salvenmoser, M. Thaler, A.-K. Gorny, M. Hrouda, G. Borgonie, P. Ladurner, BMC Dev. Biol. 2009, 9, 69.

[51] R. Gschwentner, P. Ladurner, K. Nimeth, R. Rieger, Cell Tissue Res. 2001, 304, 401.

[52] R. Gschwentner, P. Ladurner, K. Nimeth, R. Rieger, Cell Tissue Res. 2001, 304, 401.

[53] D. Thiel, M. Franz-Wachtel, F. Aguilera, A. Hejnol, bioRxiv 2018, https://doi.org/10.1101/265579

[54] K. Tessmar-Raible, F. Raible, E. Arboleda, BioEssays News Rev. Mol. Cell. Dev. Biol. 2011, 33, 165.

[55] B. Palenik, Annu. Rev. Mar. Sci. 2015, 7, 325.

[56] M. Jaubert, J.-P. Bouly, M. Ribera d'Alcalà, A. Falciatore, Curr. Opin. Plant Biol 2017, 37, 70.

[57] G. Bohn, Comptes Rendues Acad. Sci. Paris 1903, 137, 576.

[58] L. Martin, Paris C R Acad. Sci. 1907, 145, 555.

[59] F. W. Gamble, F. Keeble, J. Cell Sci. 1903, s2-47, 363.

[60] N. R. Franks, A. Worley, K. A. J. Grant, A. R. Gorman, V. Vizard, H. Plackett, C. Doran, M. L. Gamble, M. C. Stumpe, A. B. SendovaFranks, Proc. Biol. Sci. 2016, 283, 20152946.

[61] G. Fraenkel, Z. Für Vgl. Physiol. 1929, 10, 237.

[62] R. C. Starr, J. A. Zeikus, J. Phycol. 1993, 29, 1.

[63] E. Moreno, M. Nadal, J. Baguñà, P. Martínez, Evol. Dev. 2009, 11, 574.

[64] M. Chiodin, J. G. Achatz, A. Wanninger, P. Martinez, J. Exp. Zoolog. B Mol. Dev. Evol. 2011, 316, 427.

[65] C. Berney, J. Pawlowski, L. Zaninetti, Mol. Biol. Evol. 2000, 17, 1032.

[66] B. Gavilán, E. Perea-Atienza, P. Martínez, Philos. Trans. R. Soc. Lond. B. Biol. Sci. 2016, 371, 20150039.

[67] A. Hejnol, M. Obst, A. Stamatakis, M. Ott, G. W. Rouse, G. D. Edgecombe, P. Martinez, J. Baguñà, X. Bailly, U. Jondelius, M. Wiens, W. E. G. Müller, E. Seaver, W. C. Wheeler, M. Q. Martindale, G. Giribet, C. W. Dunn, Proc. Biol. Sci. 2009, 276, 4261.

[68] E. Perea-Atienza, B. Gavilán, M. Chiodin, J. F. Abril, K. J. Hoff, A. J. Poustka, P. Martinez, J. Exp. Biol. 2015, 218, 618.

[69] T. Tohmonda, A. Kamiya, A. Ishiguro, T. Iwaki, T. J. Fujimi, M. Hatayama, J. Aruga, J. True, Mol. Biol. Evol. 2018, msy122, https:// doi.org/10.1093/molbev/msy 122

[70] E. Bresslau, Verhandlungen Dtsch. Zool. Ges. 1909, 19, 314.

[71] J. Georgevitch, Arch. Zool. Expérimentale Générale 1899, 3, 343.

[72] A. S. Arroyo, D. López-Escardó, C. de Vargas, I. Ruiz-Trillo, Biol. Lett. 2016, 12, 20160674. 